\title{
AS CATÁSTROFES CLIMÁTICAS
}

DENISE DE BRUM FERREIRA ${ }^{(1)}$

As catástrofes climáticas fazem parte de um tipo de agressões para as quais as populações estão actualmente cada vez mais sensibilizadas. Em primeiro lugar porque são cada vez mais numerosas as pessoas que sofrem os seus efeitos traumatizantes e, em segundo lugar, porque há uma abundante informação, quase em tempo real na televisão, sobre as suas manifestações em qualquer ponto do Planeta e sobre as suas consequências. Também, não faltam jornais (e mesmo investigadores de renome) que não prevejam mudanças climáticas drásticas à escala global para os próximos decénios, com o efeito de estufa, o buraco do ozono e a deflorestação da Amazónia como pano de fundo. A importância dada actualmente nos grandes programas internacionais de investigação ao "Global Change" faz com que toda gente tenda a olhar mais para a evolução do clima no futuro do que para o clima actual. Esta maneira de encarar o clima torna-se um verdadeiro estado de espírito no subconsciente colectivo. A prova é que na maior parte das vezes que há notícias sobre manifestações extremas do clima (ciclones tropicais, tornados, secas, tempestades, trovoadas, chuvas intensas...), ou mesmo fenómenos menores fora do vulgar (por exemplo, um simples halo irisado à volta do Sol mais nítido do que de costume, como no dia 26 de Maio de 1995 no céu de Lisboa), não faltam comentários sobre a associação destas "anomalias" com as temidas mudanças globais.

Para tentar pôr um pouco de ordem no conceito de catástrofe climática e definir o lugar que o Homem ocupa no conceito, devemos recomendar a leitura do pequeno ensaio sobre as catástrofes climáticas que P. Pagney (1994) acaba de publicar na colecção Que sais-je? (n ${ }^{\circ}$ 2878) das Presses Universitaires de France (título francês: Les catastrophes climatiques).

A primeira parte, a mais original das três, é dedicada ao conceito de catástrofe climática do qual o Homem não é excluído. O ponto de partida é sem

(1) Professora Associada da F.L.U.L., Investigadora do Centro de Estudos Geográficos, Faculdade de Letras, Cidade Universitária, 1699 Lisboa Codex. Tel. (351-1)7940218; Fax: (351-1)7938690. 
dúvida um acontecimento "natural", de carácter excepcional pela sua intensidade e/ou extensão, e pelas suas implicações. Mas, é pela conjunção dos efeitos do fenómeno e da intervenção do homem que se mede a amplitude da crise.

A segunda parte, depois de uma rápida alusão às catástrofes da época histórica, é reservada ao tratamento sucinto de exemplos muito variados de catástrofes climáticas contemporâneas, de diferentes escalas espaço-temporais (secas, chuvas diluvianas com implicações hidrológicas, tempestades) e nas quais o homem intervém em força (voluntariamente ou não).

A terceira parte pretende mostrar que o clima, com a sua dinâmica própria e a sua variabilidade (que inclui manifestações extremas), deve ser tomado em conta no ordenamento do Planeta (a todas as escalas de trabalho). É um tema demasiado vasto para ser tratado em apenas um quinto do livro. Tudo o que se torna possível fazer em algumas páginas muito concisas, e portanto demasiado gerais, é indicar as escalas preferenciais de intervenção do homem para mitigar os riscos (mas não necessariamente anulá-los), estabelecer uma previsão (problemática) e uma prevenção (de eficácia relativa, sobretudo à escala global).

Conclusão (p. 123) não só aplicável às catátrofes climáticas: "Nestas condições - (de falta de consciência dos perigos presentes e futuros, falhas de mémoria dos perigos passados, ou mesmo de ideias claras sobre o perigo a evitar) - o ordenamento do Planeta, a todos os níveis da escala geográfica, oferece mais resistência por parte dos homens do que por parte da natureza, cujas reacções são isentas de qualquer ambiguidade"...

\section{AS CATÁSTROFES NATURAIS EM FRANÇA}

DENISE DE BRUM FERREIRA

"Meus Senhores, há já alguns anos que sofremos arrefecimentos sensíveis da atmosfera, variações súbitas nas estações do ano, tempestades e inundações extraordinárias, aos quais a França parece tornar-se cada vez mais sensível...". É desta maneira que Bruno Ledoux (1995) começa a introdução ao seu livro Les catastrophes naturelles en France (ed. Payot e Rivages, 455 p.). $O$ interesse deste discurso reside no facto de ele ter sido retirado de 
uma circular ministerial difundida em $\underline{1821}$. E é tão actual ! Basta abrir o jornal diário para se ficar com a impressão que o mundo inteiro está a entrar numa era de catástrofes sem precedentes. Também não faltam comentários pessimistas sobre uma tendência crescente da ocorrência destas catástrofes neste fim de século e sobre uma previsão alarmista da sua aceleração no século XXI.

O livro de B. Ledoux surge como um balanço da actividade da "Délégation aux risques majeurs", organismo governamental criado em 1984 e confiado ao vulcanólogo Haroun Tazieff para estudar os riscos inerentes à ocorrência de cataclismos no território francês, e para melhorar a previsão e a prevenção. O livro, extremamente bem documentado, tenta fazer o ponto do conhecimento actual dos principais riscos naturais em França (incluindo os territórios ultramarinos) a partir do inventário das catástrofes passadas.

A primeira parte situa a França no panorama mundial das catástrofes naturais. O território francês encontra-se livre dos grandes cataclismos mundiais, excepção feita dos territórios ultramarinos quanto ao risco ligado à passagem de ciclones tropicais. Todavia, os anos 80 foram ricos em catástrofes particularmente traumatizantes para os habitantes das regiões sinistradas, pouco preparados para enfrentar repetidas situações adversas, como inundações, cheias súbitas e violentas, tempestades, movimentos de terreno, avalanches...

A segunda parte apresenta um inventário das catástrofes susceptíveis de afectar com alguma frequência o território francês. Três grandes tipos de fenómenos foram analisados numa perspectiva histórica com apresentação das causas, dos sítios onde apareceram, das consequências e da gestão possível dos riscos inerentes. São as catástrofes geofísicas (sismos e vulcões), as catástrofes hidroclimáticas (ciclones, inundações e cheias rápidas, avalanches) e as catástrofes geomorfológicas (movimentos de terreno). Os fogos florestais são também contemplados, apesar de não constituirem um risco inteiramente "natural". Todavia, pela frequência de ocorrência e pela destruição que acarretam, os fogos florestais são um flagelo que origina verdadeiras catástrofes regionais.

A terceira parte é dedicada à gestão do risco, à sua filosofia e à sua evolução nos trinta últimos anos.Verifica-se que a gestão foi, até há bem pouco tempo, mais uma sucessão de respostas pontuais em situação declarada de catástrofe do que a aplicação de uma real política de gestão do risco e de previsão a longo prazo. A partir de 1982, o Estado empreendeu uma política ambiciosa e integradora de gestão dos riscos naturais em todo o território francês com metas bem definidas: inventariar as catástrofes passadas e os riscos, reforçar a investigação das causas, elaborar ferramentas legislativas destinadas a actuar no campo do ordenamento das zonas de risco, na aplicação de plano de socorro aos sinistrados e na ajuda financeira às reparações 
dos danos. A série negra de catástrofes surgidas nos últimos dez anos (os ciclones Firinga na Reunião e Hugo na Guadalupe, ambos em 1989; as tempestades na Bretanha e na Normandia em 1987 e 1990; as cheias rápidas no Grand Bornand em 1987, Nîmes em 1988 e Vaison-La-Romaine em 1992...) veio mostrar o relativo falhanço da funcionalidade desta política de previsão e prevenção dos riscos. A causa apontada em primeiro lugar pelo autor do livro é uma pesada herança de negligência e de ignorância que condiciona ainda a política actual e os centros de decisão, mas esta não explica tudo. "A análise aprofundada das catástrofes recentes revela quanto a gestão dos riscos naturais é um exercício complexo que, no momento actual, com a crise económica como pano de fundo, foi relegado para o campo da política acessória, tanto pelo Estado como pelas colectividades locais. Todavia, nada impede que as grandes catástrofes do passado não se reproduzam amanhã..." (p. 9).

\section{O HOMEM E O AMBIENTE}

DENISE DE BRUM FERREIRA

Y. Veyret e P. Pech (1993) propõem no livro L'homme et l'environnement (P.U.F., Paris, 423 p.), destinado aos estudantes dos primeiros anos do Ensino Universitário, uma abordagem verdadeiramente geográfica das relações existentes entre as sociedades humanas e o ambiente. Mas a formação dos dois autores em Geografia Física ajuda a colocar o debate longe da batalha da conservação da natureza e da abordagem ecológica dos problemas da relação Homem-ambiente. $\mathrm{Na}$ abordagem ecológica, as componentes abióticas do ambiente são estudadas só porque actuam sobre os seres vivos e em retorno, sofrem a acção destes. "O único interesse do quadro abiótico reside no fornecimento de matéria ou de energia nos ciclos de vida mas, na maior parte dos casos, ele torna-se um quadro estático" (p. 11). A abordagem utilizada no livro procura determinar o peso dos factores naturais no ordenamento do território em termos de potencialidades, de contingências induzidas e/ou de riscos associados. São também tratadas as consequências das intervenções humanas no quadro de vida e sobre a natureza. A análise sistémica é privilegiada numa perspectiva dinâmica. Pois o controlo exercido pela natureza, por certos factores de risco, certas potencialidades do meio biofísico não são 
dados adquiridos para sempre. Exemplo disto é o papel do Sol no ideal de férias, cada vez mais percebido actualmente como uma fonte de risco, ou ainda a neve, hoje mais vista como fonte de receita turística do que como factor de isolamento de uma região.

A primeira parte apresenta a Terra como um sistema, insistindo sobre o que se sabe do seu funcionamento e das interacções das diferentes partes que o compõem de maneira a mostrar as limitações dos recursos naturais que ele oferece ao Homem.

A segunda parte trata dos constrangimentos e dos riscos, os de origem natural $\mathrm{e}$ os induzidos pela actividade humana, no intuito de mostrar que o meio biofísico condiciona o ordenamento tanto como os factores económicos ou sociais. Se este facto não é tomado em conta, desequilíbrios aparecem cuja correcção (quando possível) custa à sociedade mais caro do que a prevenção. Os autores insistem sobre os efeitos de práticas de ordenamento do território mal conseguidas, acreditando na pedagogia do erro para a procura de soluções adequadas. Mostram também numerosos exemplos de modificação do ambiente que não são condenáveis. Segundo os autores, a escolha do modo de gestão do território pela sociedade deve antes de tudo responder a uma melhoria da qualidade de vida do Homem.

A terceira e última parte mostra a diversidade dos tipos de relação que existem entre o Homem e o ambiente nos países industrializados e nos países em vias de desenvolvimento.

Nos países ricos, a vulnerabilidade face aos constrangimentos impostos pela natureza e aos riscos não desaparecem com o nível de desenvolvimento económico e tecnológico. Pelo contrário, a intensificação da agricultura, o desenvolvimento a um ritmo sem precedentes das cidades fizeram aparecer problemas ambientais graves e distorsões entre planeamento e ambiente que a legislação abundante nestes últimos anos tende a minorar. Muitos exemplos franceses de intervenção e de gestão dos riscos são citados.

O tratamento das relações Homem-ambiente nos países em vias de desenvolvimento foi feito de uma maneira demasiado superficial, tendo em conta o peso do capítulo anterior e a importância do tema da degradação ambiental acelerada de certos ecosistemas tropicais, dos riscos naturais específicos e do crescimento urbano explosivo nos países pobres.

Em conclusão, temos de realçar a clareza da exposição e a variedade dos temas abordados. A tentativa de fornecer respostas às questões ambientais a qualquer escala de análise (do local ao planetário) que integram o maior número possível de factores no quadro de uma análise sistémica com abordagem geográfica é um ponto forte do livro e um bom guia metodológico de nível universitário. 